\title{
The impact of participatory management on organizational culture and performance \\ Case Study: Isfahan municipality employees
}

\author{
Omid Lavafan ${ }^{1}$,Iraj Soltani ${ }^{2}$ \\ ${ }^{1,2}$ Faculty Research of human resource management,Research Institute of Shakes Pajouh,Isfahan ,Iran \\ E-mail:o_11366@yahoo.com
}

\begin{abstract}
Increasing employee engagement through organizational culture has numerous advantages for the organization. When employees are involved in the process of making decisions, they are more cooperative in accepting them and more committed, leading to increased performance. This paper aims to evaluate the impact of participatory management on organizational culture and performance. According to the available literature and research background, three hypotheses are formed and tested. A standard questionnaire is used as the data collection tool, distributed among employees of District 6 of Isfahan Municipality. The collected data are analyzed using SPSS V.18.0 and AMOS V.20.0 software packages. The results show that participatory management has both direct and indirect, through organizational culture, impacts on organizational performance
\end{abstract}

\section{Indexing terms/Keywords}

Participatory management, organizational culture, organizational performance

\section{Academic Discipline And Sub-Disciplines}

Human Resource Management

\section{SUBJECT CLASSIFICATION}

Managment

\section{TYPE (METHOD/APPROACH)}

Case study

\section{Council for Innovative Research}

Peer Review Research Publishing System

Journal: International Journal of Management \& Information Technology

Vol. 8, No. 2

editor@cirworld.com

www.cirworld.com, member.cirworld.com 


\section{INTRODUCTION}

Human workforce, as the most valuable asset of the organization, is faced with numerous challenges in the modern world. However, by finding factors that influence performance, management and psychology experts can enhance the positive factors and reduce the negative ones (Azari and Davoudian, 2011). Participation, as an innate need in every human being, is a tie between two individuals to augment each other's efforts. The mutual exchange of information, knowledge, thoughts and ideas benefits both parties and adds to their mental abilities. Participation is the mental and emotional involvement with a group which motivates people to work together and share responsibility in achieving a common goal. Participatory management is the practice of involving employees in decision making, inviting everyone to accept responsibility for improving quality, and rewarding behavior which stratifies the customer and increases organizational performance (Davis, 2001).

Limited attention has been given to organizational culture in classic management theories. Specifically, the Theory of Human Relations Movement, the Hawthorn studies, and behaviorist theorists gave more importance to organizational culture and working values, which gradually turned organizational culture to a significant field of organizational behavior. Effective organizations have strong cultures and a set of common values. However, the true impact of a strong culture on performance depends on how consistent and compatible the culture is with the organization's circumstances. When faced with a dynamic environment, a strong and innovative culture adapts well. Thus, we can expect such a culture to increase employee satisfaction and performance and decrease the risk of quitting (Khanifar and Kashani, 2012).

The aim of this study is to determine the impact of participatory management on organizational performance. The rest of the paper is organized as follows. In the next section we review existing literature. After that the hypotheses and the conceptual model of the study a presented, followed by a discussion of our methodology. Data analysis comes in the section after that. Finally, we conclude the paper with a discussion of the results.

\section{Theoretical Background}

\section{Participatory management}

Rapid changes in the modern world, which have transformed technologies of production and providing service, call for collective wisdom in making decisions and envisioning strategies in participation systems, so that organizational survival is ensured. Participation systems have been in use for more than half a century, with countries such as Germany and Japan gaining invaluable experience after World War II (Ramezanian, 2009). Participation systems are considered as independent systems or as part of a more holistic quality management system. This management system has been tested both theoretically and practically and is currently in use in many developed and developing countries. Many experts attribute the spectacular business advances by countries in Southeast Asia to this system, sometimes referred to as Japanese Management. Several management experts in Iran believe that this system can solve existing problems such as low efficiency of the human workforce, low motivation, individual conflicts, and lack of coordination and consider it as the missing key in Iranian management (Amini, 2007).

Participation is an innate human need. Humans feel the need to belong, bond, and socialize since birth. Constructive participation can exist among two or more individuals. This leads to a bond which can benefit all parties involved. By exchanging information, knowledge, thoughts, and ideas, mental growth can be obtained. Participation is the mental and emotional involvement with a group which motivates people to work together and share responsibility in achieving a common goal (Tousi, 1999).

In another definition of participation, it is considered as a kind of sharing and involvement in decision making, planning, and execution aimed at a common goal which participants desire to achieve by cooperating with each other (Ghasemi, 2001). Participatory management is the practice of involving employees in decision making, inviting everyone to accept responsibility for improving quality, and rewarding behavior which stratifies the customer and increases organizational performance (Davis, 2001).

\section{Organizational Culture}

"Organizational Culture" is a relatively new concept which has attracted much attention from experts and researchers in the field of management. They believe that culture is the personality of an organization and therefore research on organizational culture can improve the society, just as research on personality can improve individuals (Rezaei et al., 2013).

Generally, culture is associated with the way humans view their environment and shows their perspectives and beliefs. Organizational culture is the set of common values, beliefs, assumptions, and norms held by the members of that organization. It is the relatively constant beliefs and values which are commonly respected and lead to particular behavioral patterns. Organizational culture determines the manner in which tasks are performed. It describes characteristics which distinguish organizations from each other. In other words, it is the social identity of an organization. Culture is a set of key values which the members of an organization have widely accepted (Tsui et al., 2006).

Due to its complex nature, there is no widely accepted theory or framework for analyzing it (Feyci, 2003). However, the Denison Organizational Culture Model is one of the most common models for identifying strengths and weaknesses in organizations. The main feature of this model is its ability to adapt to external changes because this can depict the 
relationship environmental needs and the organization's strategies from one side and the compatible organizational culture from the other (Ziaei, 2011).

The following cultural traits are considered in the Denison model (Mozafari et al., 2012; Denison and Nill, 2000).

Involvement: Effective organizations empower their employees, build working teams, and develop the skills of their workforce at every level of the organization. All employees are allowed to have a role in making decisions which directly affect their work. In this model, this trait is measured using (1) empowerment, (2) team-orientation, (3) capability development.

Consistency (stability and integrity): Research has shown effective organizations are stable and integrated and employee behavior stems from core values. In such organizations, leaders and followers are skilled at reaching agreements (even in case of opposing ideas) as well as coordinating and integrating organizational activities. As a result, the organization has a strong culture and influence on employee behavior. In this model, this trait is measured using (1) core values, (2) agreement, and (3) coordination and integration.

Adaptability: well-integrated organizations are hard to change. Thus, internal integration and external adaptability are considered advantages for an organization. Adaptable organizations are driven by the customers' needs, take risks, learn from their mistakes and are capable of change. They are continuously striving to improve in order to be valuable to their customers. In this model, this trait is measured using (1) creating change, (2) customer focus, and (3) organizational learning.

Mission: We might say that the most important traits of organizational culture are mission and vision. Organizations which are not aware of where they are and their current status are often led astray. Successful organizations have a clear vision of their strategic goals. In this model, this trait is measured using (1) strategic direction and intent, (2) goals and objectives, and (3) vision.

Each organization has a dominant culture with several subcultures. The dominant culture is the one accepted by most members of the organization. The strength of this culture can be determined based on the number of people that are committed to it and how committed they are to the rules and norms of this culture. The concept of organizational culture is considered as an influential factor on efficiency and performance. A good culture can increase commitment, improve ethics, and enhance performance (Rezaei, 2013).

\section{Organizational Performance}

Many managers in organizations compete with each other and look for ways to improve performance in their organization, which is a concern for most modern organizations (Benzing et al., 2005). Organizational performance is an indicator of better sales and market share (Wu et al., 2006; Molina et al., 2007). A positive organizational culture can improve organizational performance (Shirazipour, 2013).

Nili et al. (2003) provide the most popular definition of performance: the process of determining the effectiveness and efficiency of past measures. In his definition of performance measurement, Molin (2002), emphasizes management evaluation and creating value for customers and other stakeholders. In another definition Nani et al. (1990) define two major approaches to performance measurement: observed and perceived, both having their advantages and disadvantages. Observed measurements are more realistic but limited to financial values, while perceived measurements are less realistic but provide a clear description of effectiveness in the organization. These measurements allow comparisons between different industries. Therefore, perceived measurements are more extensible. Furthormore, they include analysis based on perception, which is important in social sciences (Allen and Dawson, 2008).

Sink (1991) considers performance measurement to be a complex, challenging, and important task. Organizational performance is a function of organizational efficiency and effectiveness. Thus, performance measurement is the process of quantifying efficiency and effectiveness in an organization. Performance measurements show what has happened but do not provide the reason (Rahnavard, 2008; Rahimnia et al., 2013).

\section{Hypotheses and Conceptual Model}

Increasing employee engagement through organizational culture has numerous advantages for the organization. When employees are involved in the process of making decisions, they are more cooperative in accepting them and more committed, leading to increased performance. In recent years, organizational culture as received more attention from researchers in Iran and it relationships with organizational efficiency, structure, leadership styles, and effectiveness have been considered. Limited attention has been given to the relationship between organizational culture and employee performance. The positive correlation of the two has been established previously. Figure 1 presents the conceptual model of the study and the following are hypothesized.

H1: Participatory management influences organizational culture.

H2: Participatory management influences organizational performance.

H3: Organizational culture influences organizational performance. 


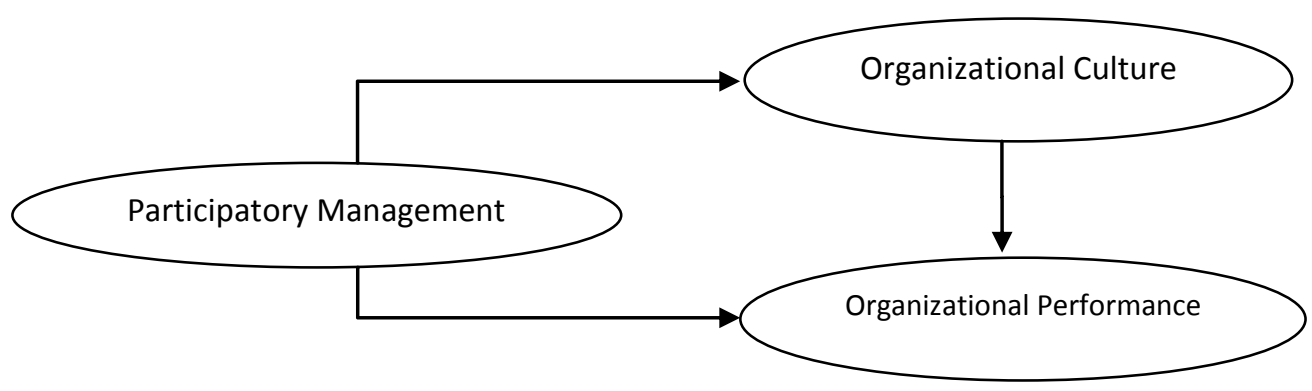

Figure 1. Conceptual model of the study

\section{Methods}

\section{Population and sample}

This is an applicative descriptive survey. The statistical population includes the employees of District 6 of Isfahan Municipality. Using random sampling, 150 copies of the questionnaire were distributed among the participants, of which 143 were acceptable upon return. The first section assesses demographic variables such as age, gender, education, and marital status. The second section, on the other hand, focuses on study variables. Answers are given on Lickert scale of 1 (completely disagree) to 5 (completely agree).

\section{Study variables}

Content validity of the questionnaire was verified by experts at the University of Isfahan. To determine the reliability of the test, Cronbach's alpha was calculated giving a result of 0.81 , which is acceptable. Cronbach's alpha for individual variables can be seen in Table 1.

Table1. Cronbach's alpha

\begin{tabular}{cccc}
\hline Variable & $\begin{array}{c}\text { Number of } \\
\text { Questions }\end{array}$ & Dimensions & $\begin{array}{c}\text { Cronbach's } \\
\text { alpha }\end{array}$ \\
\hline $\begin{array}{c}\text { Organizational } \\
\text { culture }\end{array}$ & 20 & Involvement, constancy, adaptability, mission & $0 / 84$ \\
$\begin{array}{c}\text { Participatory } \\
\text { management }\end{array}$ & 7 & - & $0 / 76$ \\
$\begin{array}{c}\text { Employee } \\
\text { performance }\end{array}$ & 7 & - & $0 / 80$ \\
\hline
\end{tabular}

\section{Data Analysis}

\section{Confirmatory factor analysis}

The first step is to determine the fit for the measurement model. Table 2 presents the fit indices of the models.

Table 2- fit indices of the measurement model

\begin{tabular}{cccc}
\hline Variable & $\begin{array}{c}\text { Organizational } \\
\text { Culture }\end{array}$ & $\begin{array}{c}\text { Participatory } \\
\text { Management }\end{array}$ & Performance \\
Index & $2 / 57$ & $1 / 87$ & $1 / 32$ \\
CMIN/DF & $0 / 05$ & $0 / 006$ & $0 / 001$ \\
RMR & $0 / 90$ & $0 / 94$ & $0 / 98$ \\
GFI & $0 / 88$ & $0 / 91$ & $0 / 94$ \\
AGFI & $0 / 95$ & $0 / 95$ & $0 / 99$ \\
IFI & $0 / 98$ & $0 / 99$ & $0 / 99$ \\
TLI & $0 / 95$ & $0 / 96$ & $0 / 99$ \\
NFI & $0 / 98$ & $0 / 95$ & $0 / 99$ \\
CFI & & & \\
\hline
\end{tabular}

The measurement models are good-fitting i.e. fit indices confirm the fact that the models provide adequate fit for the data. All factor loadings are greater than 0.5 , with significance level equal to 0.000 . 


\section{Structural Equation Modeling}

After confirming the goodness of fit for the measurement models in the first step, the second step is to test the hypotheses using structural equation modeling. Model fit indices are shown in Table 3.

Table 3. Model fit indices

\begin{tabular}{ccccccccc}
\hline RMR & IFI & CFI & NFI & AGFI & GFI & RMSEA & CMIN/df & CMIN \\
\hline $0 / 03$ & $0 / 97$ & $0 / 97$ & $0 / 95$ & $0 / 90$ & $0 / 94$ & $0 / 06$ & $3 / 15$ & $73 / 44$ \\
$\begin{array}{c}\text { Near } \\
\text { zero }\end{array}$ & $0 / 90>$ & $0 / 90>$ & $0 / 90>$ & $0 / 90>$ & $0 / 90>$ & $0 / 08<$ & $1>, 5<$ & $\begin{array}{c}\text { Acceptable } \\
\text { region }\end{array}$
\end{tabular}

The results of Table 3 can be interpreted as follows.

The standard estimation model from Amos indicate that the path analysis model is adequate. The chi-square is equal to 3.15, falling between 1 and 5. The RMSEA equals 0.05, which is adequate. Furthermore, GFI, AGFI, NFI, CFI, and IFI are all greater than 0.90. Finally, the RMR is near zero. The values for the fit indices are all in the acceptable region, which proves the models provide adequate fit for the data. The hypotheses along with their partial indicators and regression coefficients can be seen in Table 4.

Table 4. Hypotheses test results

\begin{tabular}{clccccc}
\hline Hypothesis & & $\begin{array}{c}\text { Sample } \\
\text { size }\end{array}$ & $\begin{array}{c}\text { Significance } \\
\text { value }\end{array}$ & $\begin{array}{c}\text { Critical } \\
\text { value }\end{array}$ & $\begin{array}{c}\text { Correlation } \\
\text { coefficient }\end{array}$ & $\begin{array}{c}\text { Result } \\
\text { varticipatory management }\end{array}$ \\
& $\longrightarrow$ Culture & 143 & $0 / 000$ & $11 / 84$ & $0 / 49$ & Confirm \\
Participatory management & $\longrightarrow$ Performance & 143 & $0 / 000$ & $10 / 62$ & $0 / 39$ & Confirm \\
Culture & $\longrightarrow$ Performance & 143 & $0 / 000$ & $13 / 87$ & $0 / 56$ & Confirm \\
\hline
\end{tabular}

\section{FINDINGS}

The results of testing the hypotheses are as follows.

$\mathrm{H1}$ : Participatory management influences organizational culture. Path analysis proved that, with a 0.49 coefficient, this is true.

H2: Participatory management influences organizational performance. Path analysis proved that, with a 0.39 coefficient, this is true.

H3: Organizational culture influences organizational performance. Path analysis proved that, with a 0.56 coefficient, this is true.

\section{DISCUSSION AND CONCLUSION}

To enable participatory management (participation system) we suggest that employees become familiar with the philosophy and goals of participation system in other countries and organizations as well as their roles in the sytem. Moreover, managers need to create a shared vision and establish mutual trust among employees and instructors and encourage everyone to participate in the process.

Also, to organize participation efforts, we suggest creating regulations and guidelines as well as setting goals and building a structure.

Since participatory management on flexibility and human relations creating "participatory management" working groups is a must.

In order to gradually evolve the participation system, we suggest starting with volunteering individuals and moving towards teams. Informing others of the benefits of participatory management, creating a sense of self-belief and self-esteem in employees, paying attention to career development are among the approaches recommended for establishing participatory management.

The outcomes and results of participation must be clear so that everyone will be aware of the benefits.

Finally, we suggest developing a culture of participation, where all managers, regardless of their position, are involved in the process of making decisions.

Similar to any scientific work, this study faced some challenges and limitations. Identifying such limitations can help in improving interpreting the results and improving the quality of the work. The following were faced over the course of conducting this study.

The model was only tested on employees of one organization (District 6 of Isfahan Municipality). 
Other variables can be added to the model to make in more comprehensive.

The study is only focused on the city of Isfahan, which makes extending the results to other cities with different cultures difficult.

The data were collected using only questionnaires, while other more accurate tools, such as interviews, might be preferable in future studies.

The demographics of the study form the last limitation. It is not known whether other methods will yield the same results.

\section{REFERENCES}

[1] Amini ,M. 2007. The impact of participatory management on effectiveness perceived by experts in Forrest Management Department, Modern Agricultural Findings, vol.2, issue.1, pp. 96-108.

[2] Azari ,Gh., Davoudian A.H. 2011. Comparison of burnout and skeletal disorders in computer using employees, Official Report.

[3] Jahanian, R. 2009. Approaches to developing participatory management in education, Khorasgan University Journal, issue.21, pp. 153-174.

[4] Khanifar, H., Kashani M. 2012. The impact of organizational culture on efficiency, MSc Thesis.

[5] Rahimnia ,F., Kafashpour A., Pourreza M. 2013. The mediating role of marketing capabilities in the relationship between strategic alignment and organizational performance, 2nd International Conference on Management, Entrepreneurship, and Economic Development.

[6] Rezaei, H., Khazaei J., Lashki, K., Amani M., Kazemi R. 2013. A model of organizational culture and knowledge sharing and agility, Crisis Management Quarterly, issue.3, pp. 59-67

[7] Rahnavard, F. 2008. Factors affecting performance in the public sector, Human and Management Studies Journal, vol. 8 , issue. 4

[8] Shirazi, A., Pour S. 2013. The impact of organizational error management on organizational performance, 2nd International Conference on Management, Entrepreneurship, and Economic Development.

[9] Ziaei ,M.S., Roshandel T., Nargesian A. 2011. The relationship between organizational culture and commitment in employees of Tehran Libraries: using the Denison Model, Librarians and Information Journal, issue. 55, pp. 4972.

[10] Tousi, M.A. 1999. Atmosphere management, Official Report.

[11] Ghasemipour, E. 2001. Public participation in education, Education Research Center. 